\title{
Experience of a single institution with femoral vein homograft as right ventricle to pulmonary artery conduit in stage 1 Norwood operation
}

\author{
T. K. Susheel Kumar, MD, ${ }^{a}$ David Zurakowski, MS, PhD, ${ }^{b}$ Mario Briceno-Medina, MD, \\ Aditya Shah, MD, ${ }^{a}$ Shyam Sathanandam, MD, ${ }^{c}$ Jerry Allen, CCP, ${ }^{\mathrm{a}}$ Hitesh Sandhu, MD, \\ Vijaya M. Joshi, MD, ${ }^{\mathrm{c}}$ Umar Boston, MD, ${ }^{\mathrm{a}}$ and Christopher J. Knott-Craig, MD ${ }^{\mathrm{a}}$
}

\section{ABSTRACT}

Objective: Femoral vein homograft can be used be used as valved right ventricle to pulmonary artery conduit in the Norwood operation. We describe the results of this approach, including pulmonary artery growth and ventricular function.

Methods: A retrospective chart review of 24 consecutive neonates with hypoplastic left heart syndrome or complex single ventricle undergoing this approach between June 2012 and December 2017 was performed. Conduit valve competency and ventricular function were estimated using transthoracic echocardiogram, and pulmonary artery growth was measured using Nakata's index. Changes in ventricular function pre-Glenn and at latest follow-up were assessed by ordinal logistic regression with a general linear model to account for the correlation within the same patient over time.

Results: Median age at surgery was 4 days, and mean weight was $3 \mathrm{~kg}$. There was no interstage mortality. A total of 21 patients have undergone Glenn operation, and 9 patients have completed the Fontan operation. None of the conduits developed thrombosis. Sixty-three percent of conduits remained competent in the first month, and 33\% remained competent after 3 months of operation. Catheter interventions on conduits were necessary in 14 patients. Median Nakata index at preGlenn catheterization was $228 \mathrm{~mm}^{2} / \mathrm{m}^{2}$ (interquartile range, $107-341 \mathrm{~mm}^{2} / \mathrm{m}^{2}$ ). Right ventricular function was preserved in $83 \%$ of patients at a median follow-up of 34 (interquartile range, 10-46) months.

Conclusions: Femoral vein homograft as a right ventricle to pulmonary artery conduit in the Norwood operation is safe and associated with good pulmonary artery growth and preserved ventricular function as assessed by subjective echocardiography. Catheter intervention of the conduit may be necessary. ( $\mathrm{J}$ Thorac Cardiovasc Surg 2019;158:853-62)

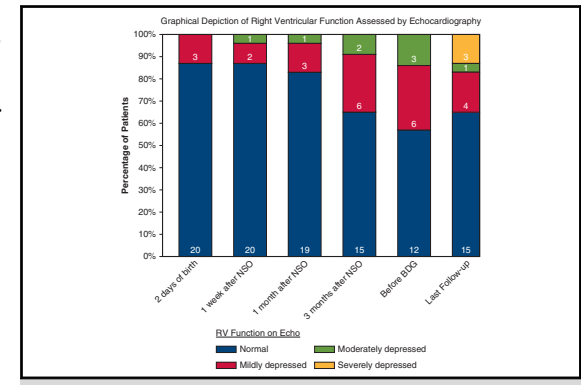

Graphical depiction of right ventricular function on serial echocardiography.

\section{Central Message}

Femoral vein as pulmonary conduit in stage 1 Norwood operation is associated with good growth of the branch pulmonary arteries and preserved ventricular function as assessed by serial echocardiogram.

\section{Perspective}

PTFE tube used as pulmonary conduit in the Norwood operation is associated with suboptimal PA growth and deterioration of right ventricular function. Use of the femoral vein is associated with good PA growth and preservation of ventricular function as assessed by echocardiogram. Catheter reintervention on conduit may be necessary. Further studies are required.

See Commentaries on pages 863 and 865.

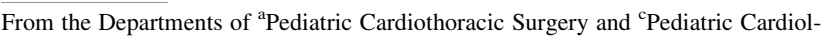
ogy, Le Bonheur Children's Hospital and University of Tennessee Health Science Center, Memphis, Tenn; and ${ }^{\mathrm{b}}$ Departments of Anesthesiology and Surgery, Boston Children's Hospital, Harvard Medical School, Boston, Mass.

Drs Zurakowski and Briceno-Medina contributed equally to the study.

Read at the 98th Annual Meeting of The American Association for Thoracic Surgery, San Diego, California, April 28-May 1, 2018.

Received for publication April 26, 2018; revisions received Feb 21, 2019; accepted for publication March 6, 2019; available ahead of print June 14, 2019.

Address for reprints: T. K. Susheel Kumar, MD, Department of Pediatric Cardiothoracic Surgery, Le Bonheur Children's Hospital, University of Tennessee Health Science Center, Memphis, TN 38103 (E-mail: tskumar@uthsc.edu). $0022-5223 / \$ 36.00$

Copyright (C) 2019 by The American Association for Thoracic Surgery https://doi.org/10.1016/j.jtcvs.2019.03.123
}

In 2003, Sano and colleagues ${ }^{1}$ reported improved outcomes with the use of the right ventricle (RV) to pulmonary artery (PA) conduit as a source of pulmonary blood flow during the Norwood stage 1 operation. The Single Ventricle

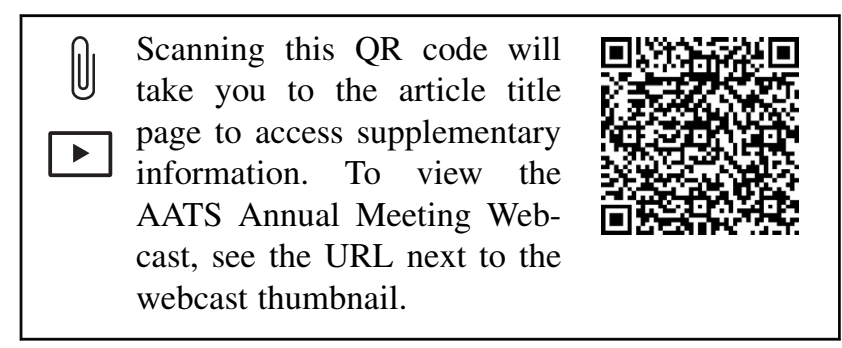




$$
\begin{aligned}
& \text { Abbreviations and Acronyms } \\
& \text { BDG = bidirectional Glenn } \\
& \text { CPB }=\text { cardiopulmonary bypass } \\
& \text { ECMO = extracorporeal membrane oxygenation } \\
& \text { FVH }=\text { femoral vein homograft } \\
& \text { HLHS }=\text { hypoplastic left heart syndrome } \\
& \text { IQR }=\text { interquartile range } \\
& \text { MRI }=\text { magnetic resonance imaging } \\
& \text { OHT }=\text { orthotopic heart transplantation } \\
& \text { PA }=\text { pulmonary artery } \\
& \text { PTFE }=\text { polytetrafluoroethylene } \\
& \text { RV }=\text { right ventricle } \\
& \text { SVR } \\
& \text { TR single ventricle reconstruction }
\end{aligned}
$$

Reconstruction (SVR) trial confirmed an improvement in transplantation-free survival at 12 months among the group that received the RV to PA conduit in the form of a polytetrafluoroethylene (PTFE) graft compared with the modified Blalock-Taussig-Thomas shunt. ${ }^{2}$ However, a follow-up of the study patients revealed that by 3 years the transplantation-free survival was no longer significantly different between the shunt groups, changes that have been due to the incision over the RV or volume overload from the free insufficiency of a valveless conduit. ${ }^{3,4}$ In addition, the PTFE tube is associated with proximal and distal stenosis, thrombosis, and distortion of the pulmonary arteries, leading to suboptimal branch PA growth and decreased pulmonary blood flow. ${ }^{1,4}$ The femoral vein homograft (FVH) (CryoLife Inc, Kennesa, $\mathrm{Ga}$, and LifeNet Inc, Virginia Beach, Va) is a naturally valved homograft, is widely available, and offers potential advantages over the PTFE tube as an RV to PA conduit. ${ }^{5}$ It has a natural endothelial lining that makes it more hemostatic and less thrombogenic. It is also more pliable than PTFE, which may result in less distortion of branch pulmonary arteries. We hypothesized that the use of valved FVH as RV to PA conduit in stage 1 operation should theoretically decrease the conduit insufficiency, result in better branch PA growth, and decrease risk of RV dysfunction, both early and late. The FVH has been our choice of RV to PA conduit for stage 1 Norwood operation since June of 2012, and we describe our experience in a series of 24 consecutive patients who underwent the stage 1 Norwood operation with the FVH as an RV to PA conduit. ${ }^{6,7}$

\section{PATIENTS AND METHODS}

Consecutive patients who underwent stage 1 Norwood operation with the use of the FVH as an RV to PA conduit between June 2012 and December 2017 were included in the longitudinal study. Neonates who received the Blalock-Taussig-Thomas shunt as part of stage 1 Norwood operation (5 patients during this time period) or patients who received Norwood operation with an RV to PA conduit as a stage toward biventricular

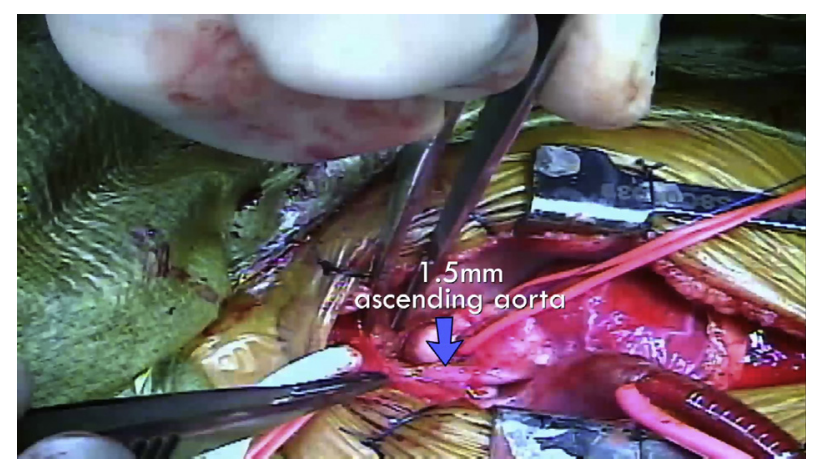

VIDEO. 1. Our technique of using a valved FVH as an RV to PA conduit during the Norwood stage 1 operation. Video available at: https://www. jtcvs.org/article/S0022-5223(19)30975-4/fulltext.

repair were excluded. The institutional review board approved the study. Twenty-three infants with a diagnosis of hypoplastic left heart syndrome (HLHS) and 1 infant with complex hypoplastic RV were the subjects of this study.

\section{Operative Procedure}

Details regarding operative techniques have been described by our group (Video 1). ${ }^{6,7}$ In brief, after placement on cardiopulmonary bypass (CPB) and cooling to deep hypothermia, the ductus arteriosus was ligated, the main PA was transected, and the distal PA was closed with a patch of pulmonary homograft. The distal end of a valved segment of FVH was then anastomosed to an opening anterior and slightly leftward over the PA confluence. During a brief period of circulatory arrest, the neoaortic arch was constructed. The proximal anastomosis of the FVH to an opening on the RV infundibulum was performed during rewarming. After weaning from CPB, banding of the RV to PA conduit (using a sleeve of 6-mm PTFE graft for patients weighing $>3 \mathrm{~kg}$ and 5-mm PTFE for patients weighing $<3 \mathrm{~kg}$ ) was performed proximal to the femoral valve if the FVH was considered oversized for the patient while aiming for an arterial oxygen saturation in the low 80s. Banding of the conduit was performed in 4 of the 24 patients. The chest was closed in a delayed manner in most patients. Low-dose dopamine ( 3 to $5 \mu \mathrm{g} / \mathrm{kg} / \mathrm{min}$ ) and calcium infusion ( 5 to $10 \mathrm{mg} / \mathrm{kg} / \mathrm{h}$ ) were the most commonly used inotropes with low-dose epinephrine $(0.03 \mu \mathrm{g} / \mathrm{kg} / \mathrm{min})$ used only occasionally.

\section{Follow-up}

Periodic transthoracic echocardiograms were performed on all patients to evaluate the RV to PA conduit (both stenosis and insufficiency). The competency of the RV to PA conduit was graded as none, mild, moderate, or severe insufficiency. The FVH was considered competent if there was no or only mild insufficiency.

Initial measurements of PA size were carried out using echocardiogram. The proximal branch PA dimensions were measured from the parasternal short-axis view. Subsequent measurements of the PA size were carried out at pre-Glenn catheterization using PA angiography with the anterior posterior camera in a $30^{\circ}$ to $45^{\circ}$ caudal projection with a $15^{\circ}$ right anterior oblique or left anterior oblique tilt to line up the branch pulmonary arteries along the long axis and lateral camera in a $90^{\circ}$ lateral projection. The Nakata index was calculated on the basis of the average PA size measurements in 2 orthogonal planes and was considered good if the value was in excess of $200 \mathrm{~mm}^{2} / \mathrm{m}^{2} .{ }^{8} \mathrm{In}$ addition, patients were referred for cardiac catheterization before stage 2 operation if there were concerns of progressive stenosis of the RV to PA conduit or recoarctation of the aorta. We prefer to do the stage 2 operation in the form of bidirectional Glenn (BDG) operation at 3 to 4 months of age. We did not face any challenges from the FVH during chest reentry at time of BDG operation. The RV to PA conduit was well leftward of the midline 
and safely divided between ligatures on CPB. The ligated ends were usually reinforced with Prolene sutures. We also made sure to not leave behind a long blind distal stump. We prefer to do the third-stage operation as a nonfenestrated extracardiac conduit Fontan operation between 2 and 3 years of age.

Periodic transthoracic echocardiograms were performed on all patients to evaluate the degree of tricuspid regurgitation (TR) and function of RV at different time points. Subjective assessment of RV function was performed serially by 2 experienced cardiologists and graded as normal, mildly depressed, moderately depressed, or severely depressed. RV function was considered preserved if the function was normal or only mildly depressed on subjective echocardiographic assessment.

Median follow-up period was 34 (interquartile range [IQR], 10-46) months. The method for determining follow-up was based on the last known clinic visit. Of the 24 patients, as of December 2017, 3 have died and the remaining 21 are followed up in the clinic.

\section{Statistical Analysis}

Continuous data were tested for normality using the KolmogorovSmirnov goodness-of-fit test, and skewed variables are summarized using the median and IQR and compared using nonparametric methods; for variables not departing from a normal Gaussian-shaped distribution, the mean and standard are reported as summary statistics. Changes in RV function measured on echocardiography across 6 time points (2 days of birth, 1 week after Norwood Sano operation, 1 month after Norwood Sano operation, 3 months after Norwood Sano operation, before BDG, and last follow-up) were assessed using ordinal logistic regression within the general linear model framework with an ordered response in RV function (normal, mildly depressed, moderately depressed, severely depressed) with time treated as a categoric factor and significance determined by the Wald test with Bonferroni adjustment to account for multiple comparisons. Estimation of $95 \%$ confidence intervals for simple proportions, such as the catheter reintervention rate, was determined using Wilson's method. McNemar's test was applied to testing change in moderate to severe RV dysfunction between pre- and post-Glenn. The Nelson-Aalen estimator was used to analyze all repeated catheterization-based reinterventions within the same patient after stage 1 to determine the cumulative hazard based on the sum of reintervention events. The tick marks in the cumulative hazard figure represent time intervals that correspond to censoring. ${ }^{9}$ Statistical analyses were performed using R with the "survfit" function such that the data were formatted so that each reintervention would be incorporated into the Nelson-Aalen cumulative hazard (R software version 2.41-3; R Project for Statistical Computing, Vienna, Austria). Stata was used for other statistical analyses including assessing changes over time in RV function as measured on serial echocardiograms (version 15.0, StataCorp LP, College Station, Tex). All reported $P$ values are 2-tailed with a Bonferroni adjusted significance level to account for multiple comparisons.

\section{RESULTS}

\section{Demographic and Perioperative}

Approximately one quarter of the patients with a diagnosis of HLHS demonstrated restrictive atrial septum requiring balloon atrial septostomy (Table 1). Three patients underwent an initial hybrid operation before stage 1 Norwood operation. All the 24 patients underwent stage 1 operation with FVH as RV to PA conduit with the size of the FVH varying between 5 and $6 \mathrm{~mm}$. All patients demonstrated stable postoperative hemodynamics except for 1 with documented severe noncompaction of RV who required a short run of extracorporeal membrane oxygenation (ECMO) in the postoperative period (Table 2). Mean inotrope score in the first 24 hours after operation was
TABLE 1. Demographics of study patients

\begin{tabular}{lc}
\hline \multicolumn{1}{c}{ Demographics $(\mathbf{n}=\mathbf{2 4})$} & Values \\
\hline Gestational age, wk & $39(38-39.5)$ \\
Fetal diagnosis & $15 / 24(63)$ \\
\hline $\begin{array}{l}\text { Restrictive atrial septum requiring balloon atrial } \\
\quad \text { septostomy }\end{array}$ & $6 / 24(25)$ \\
Preoperative intubation & $11 / 24(46)$ \\
Hybrid operation & $3 / 24(13)$ \\
Age at Norwood-Sano operation, d & $4(2-6)$ \\
Range, d (3 hybrids) & $1-62$ \\
Weight at Norwood-Sano operation, kg & $3.1 \pm 0.5$ \\
\hline Weight $<2.5$ kg & $4 / 24(17)$ \\
Diagnosis & \\
$\quad$ MS-AS & $7 / 24(29)$ \\
MS-AA & $6 / 24(25)$ \\
MA-AA & $10 / 24(42)$ \\
Other & $1 / 24(4)$ \\
\hline Size of ascending aorta, mm & $2.9 \pm 1.1$ \\
Interstage mortality & 0 \\
Chromosomal anomalies (Jacobsen, Turner, & $3 / 24(13)$ \\
22q11 del) & \\
Extracardiac anomalies (hydrocephalus and LPA & $2 / 24(8)$ \\
sling, microcephalus) & \\
\hline
\end{tabular}

Values are median (IQR), $\mathrm{n} / \mathrm{N}(\%)$, or mean \pm SD. Complete data set. $M S$, Mitral stenosis; $A S$, aortic stenosis; $A A$, aortic atresia; $M A$, mitral atresia; $L P A$, left pulmonary artery

7.8. Postoperative bleeding was minimal, and although most patients were discharged on aspirin, our threshold for discontinuing anticoagulation measures during the interstage period was low, for example when the patient needed a gastrostomy tube placement.

\section{Survival After Norwood Operation}

There was no interstage mortality. Twenty-one patients progressed to BDG operation (Figure E1). Two patients were not considered candidates for BDG or orthotopic heart transplantation (OHT) because of progressive hydrocephalus in 1 patient and progressive pulmonary hypertension in 1 patient with Turner syndrome. Both patients died of sepsis at 10 months of age. One patient is awaiting BDG operation. One patient developed recurrent episodes of myocarditis with deterioration of RV function and required $\mathrm{OHT}$ after BDG. A second patient with documented severe noncompaction of the RV (the only patient who required brief ECMO support in the postoperative period) continued to deteriorate after BDG and ultimately died because she was not a candidate for OHT (high antibody titers). Ten patients are presently awaiting Fontan operation.

\section{Femoral Vein Homograft Function}

Serial assessment of the FVH as an RV to PA conduit demonstrated preservation of valve function in approximately 
TABLE 2. Perioperative data

\begin{tabular}{lc}
\hline \multicolumn{1}{c}{ Perioperative data } & Values \\
\hline CPB time, min & $171 \pm 28$ \\
Crossclamp time, min & $59 \pm 12$ \\
\hline DHCA time, min & $42 \pm 7$ \\
FVH sizes & \\
$\quad 5$ mm & $13 / 24(54)$ \\
6 mm & $11 / 24(46)$ \\
\hline Banding of FVH & $4 / 24(17)$ \\
Open chest & $17 / 24(71)$ \\
\hline Delayed sternal closure, d & $1(0-2)$ \\
Chest tube duration, d postoperative & $3 \pm 2$ \\
Chest tube output first day, mL/kg/h & $1.1 \pm 0.5$ \\
Inotrope score within first $24 \mathrm{~h}$ & $7.8 \pm 2.2$ \\
ECMO postcardiotomy & $1 / 24(4)$ \\
Postoperative anticoagulation, within $7 \mathrm{~d}$ & \\
None & $9 / 24(38)$ \\
Heparin & $8 / 24(33)$ \\
ASA & $5 / 24(21)$ \\
Heparin + ASA & $2 / 24(8)$ \\
ASA at discharge & $24 / 24(100)$ \\
\hline
\end{tabular}

Values are median $(\mathrm{IQR}), \mathrm{n} / \mathrm{N}(\%)$, or mean $\pm \mathrm{SD}$. Inotropic score is \{ dopamine $(\mu \mathrm{g} /$ $\mathrm{kg} / \mathrm{min})+$ dobutamine $(\mu \mathrm{g} / \mathrm{kg} / \mathrm{min})+100 \times$ epinephrine $(\mu \mathrm{g} / \mathrm{kg} / \mathrm{min})\}$. Complete data set. $C P B$, Cardiopulmonary bypass; $D H C A$, deep hypothermic circulatory arrest; $F V H$, femoral vein homograft; $E C M O$, extracorporeal membrane oxygenation; $A S A$, acetylsalicylic acid.

$63 \%$ of the patients in the first month after stage 1 Norwood Sano operation. By 3 months, only $33 \%$ of the conduits remained competent (Table 3). Fourteen of the 24 patients $(58 \%)$ had catheterization-based reinterventions in the form of stenting or balloon angioplasty (Figure 1). Reinterventions were most common in the time interval between 90 and 150 days after stage I, as shown by the cumulative hazard function based on the Nelson-Aalen estimator (Figure E2). Approximately one quarter of the patients required stenting of the FVH (3 proximal, 3 distal, and 1 at center of graft) with 1 patient receiving 2 stents. We never experienced any issues of thrombosis with the FVH.

\section{Pulmonary Artery Growth}

All patients demonstrated favorable hemodynamic data at pre-Glenn catheterization. The median value of Nakata index, a surrogate of size of branch pulmonary arteries, was $228 \mathrm{~mm}^{2} / \mathrm{m}^{2}$ (IQR, $107-341 \mathrm{~mm}^{2} / \mathrm{m}^{2}$ ). Eleven of the 19 patients (excluding the 2 hybrid patients) exhibited a Nakata index above $200 \mathrm{~mm}^{2} / \mathrm{m}^{2}$ (Table 4). No patient required surgical intervention on the branch pulmonary arteries at time of BDG operation. At present, 9 of the 21 patients have completed Fontan operation. All 9 patients exhibited favorable hemodynamic data at pre-Fontan evaluation. The median Nakata index remained consistent at $231 \mathrm{~mm}^{2} / \mathrm{m}^{2}$, with 6 of the 9 patients demonstrating an index above $200 \mathrm{~mm}^{2} / \mathrm{m}^{2}$. The function of the RV was well preserved at an impressive cardiac index of $4.5 \pm 0.7 \mathrm{~L} /$ $\mathrm{min} / \mathrm{m}^{2}$ (Table 5). In addition, none of our patients required intervention on the branch pulmonary arteries at the time of BDG or Fontan operation. Transcatheter intervention was needed in the form of bilateral branch PA plasty on only 1 patient during the interstage period. Two patients needed left PA angioplasty, and 2 patients received stents in the left PA between stage 2 and stage 3. No patient has needed any transcatheter intervention following Fontan operation (Table E1).

TABLE 3. Echocardiographic data

\begin{tabular}{|c|c|c|c|c|c|c|}
\hline Echocardiographic data & $\begin{array}{c}\text { Prior } \\
\text { Norwood Sano } \\
\text { operation }\end{array}$ & $\begin{array}{c}1 \text { wk after } \\
\text { Norwood Sano } \\
\text { operation }\end{array}$ & $\begin{array}{c}1 \text { mo after } \\
\text { Norwood Sano } \\
\text { operation }\end{array}$ & $\begin{array}{c}3 \text { mo after } \\
\text { Norwood Sano } \\
\text { operation }\end{array}$ & $\begin{array}{c}\text { Before } \\
\text { BDG }(n=21)\end{array}$ & $\begin{array}{l}\text { Last follow-up } \\
\quad(n=23)\end{array}$ \\
\hline \multicolumn{7}{|l|}{ RV function } \\
\hline Normal & 20 & 20 & 19 & 15 & 12 & 15 \\
\hline Mildly depressed & 3 & 2 & 3 & 6 & 6 & 4 \\
\hline Moderately depressed & & 1 & 1 & 2 & 3 & 1 \\
\hline Severely depressed & & & & & & 3 \\
\hline \multicolumn{7}{|l|}{ TR grade } \\
\hline None & 6 & 4 & 2 & 2 & 2 & 7 \\
\hline Mild & 17 & 18 & 18 & 18 & 15 & 12 \\
\hline Moderate & & 1 & 3 & 3 & 4 & 4 \\
\hline \multicolumn{7}{|l|}{ Sano insufficiency } \\
\hline None & & 12 & 7 & 3 & & \\
\hline Mild & & 11 & 8 & 5 & 5 & \\
\hline Moderate & & 1 & 7 & 6 & 6 & \\
\hline Severe & & & 2 & 10 & 10 & \\
\hline
\end{tabular}

Complete data set. RV function and TR grade were based on 23 patients with RV as single ventricle. The Sano insufficiency was based on all the 24 patients who underwent Norwood Sano operation. $B D G$, Bidirectional Glenn; $R V$, right ventricle; $T R$, tricuspid regurgitation. 


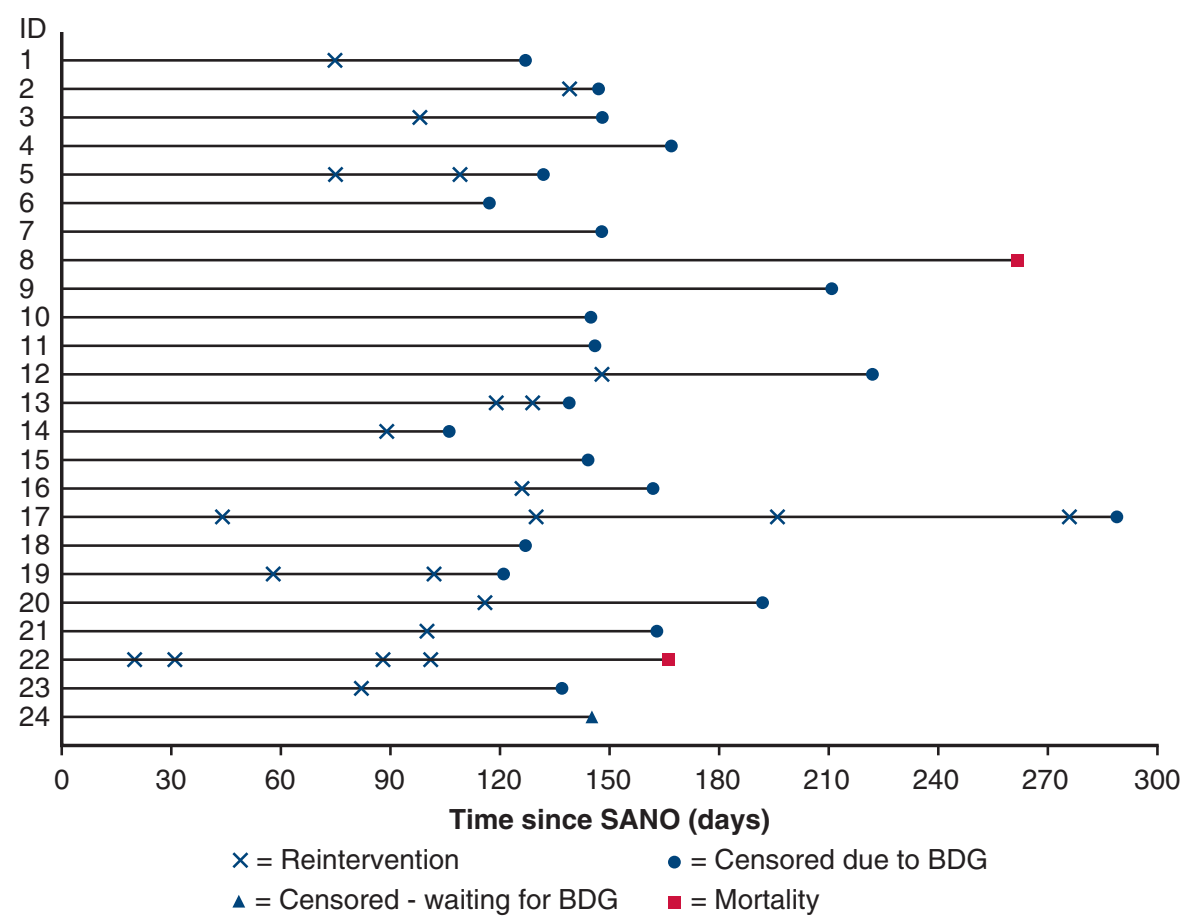

FIGURE 1. Depiction of follow-up, censoring, and outcomes for all patients in the study cohort. Catheter intervention was necessary in 14 of the 24 patients. Among a total of 23 reinterventions, the median time from stage 1 was 100 days with a range of 20 days (earliest) to 276 days (latest) and an IQR of 75 to 129 days. $B D G$, Bidirectional Glenn; SANO, Norwood-Sano operation.

\section{Right Ventricular Function}

The function of the single ventricle ( $\mathrm{RV}$ in 23 patients and LV in 1 patient) was preserved in most patients after stage 1 Norwood operation and through stage 2 and stage 3 (Table 3). Twenty of the 24 patients continued to have good function (ie, normal or only mildly depressed function) of the single ventricle at a median follow-up period of 34 (IQR, 10-46) months (Figure 2). Three patients of $21(14 \%)$ had moderate RV dysfunction before BDG, whereas 4 of 24 had moderate or severe RV dysfunction

TABLE 4. Pre-Glenn catheterization evaluation

\begin{tabular}{lc}
\hline \multicolumn{1}{c}{ Variable $(\mathbf{n}=\mathbf{2 1})^{*}$} & Values \\
\hline Age at pre-Glenn catheterization, mo & $4 \pm 2$ \\
Mean PA pressure, $\mathrm{mm} \mathrm{Hg}$ & $16.9 \pm 5$ \\
PVR, Wood units. ${ }^{2}$ & $1.9 \pm 0.8$ \\
Qp:Qs & $1.1 \pm 0.5$ \\
RVEDP, $\mathrm{mm} \mathrm{Hg}$ & $9.3 \pm 2.2$ \\
Oxygen saturations, $(\%)$ & $75 \pm 6.4$ \\
Cardiac index, $\mathrm{L} / \mathrm{min}^{2} \mathrm{~m}^{2}$ & $3.7 \pm 1.1$ \\
Nakata index $\left(\mathrm{mm}{ }^{2} / \mathrm{m}^{2}\right)$ & \\
$\quad$ At birth & $99.7(87-118)$ \\
Pre-Glenn $($ excluding hybrids, $\mathrm{n}=19)$ & $228(107-341)$ \\
\hline
\end{tabular}

Values are median (IQR), $\mathrm{n} / \mathrm{N}(\%)$, or mean $\pm \mathrm{SD}$. Complete data set. $P A$, Pulmonary artery; $P V R$, pulmonary vascular resistance; $Q p$, pulmonary blood flow; $Q s$, systemic blood flow; RVEDP, right ventricular end-diastolic pressure. *Two patients were not considered for BDG, and 1 patient is yet to undergo catheterization. at last follow-up $(17 \%)(P=.19$, McNemar's test). When accounting for the correlation within the same patient over time as a random effect in the model, ordinal logistic regression indicated no significant differences in grade of RV function on echocardiography at each time point compared with pre-BDG ( 2 days of birth, $P=.12$; 1 week after Norwood Sano operation, $P=.156 ; 1$ month after Norwood Sano operation, $P=.363 ; 3$ months after Norwood Sano operation: $P=1$; at last follow-up, $P=1$ ). Ventricular function deteriorated in 1 patient with Turner syndrome and progressive pulmonary hypertension and in 1 patient with progressive hydrocephalus and complex airway issues. Ventricular function declined rapidly in a third patient with documented severe noncompaction of $\mathrm{RV}$ and a fourth patient who developed recurrent myocarditis requiring OHT. Likewise, the tricuspid valve was preserved in most patients (Table 3 ).

\section{DISCUSSION}

The Norwood operation with the Blalock-TaussigThomas shunt as source of pulmonary blood flow was associated with substantial interstage mortality. ${ }^{10-12}$ Sano and colleagues ${ }^{1}$ subsequently described improved postoperative hemodynamics and outcomes with the use of RV to PA conduits in the form of valveless PTFE tubes ( 5 to $6 \mathrm{~mm}$ ) in 2003. This led to widespread use of the RV to PA conduit as a source of pulmonary blood flow in stage 1 Norwood operation, and improved results were confirmed in the 
TABLE 5. Pre-Fontan catheterization evaluation

\begin{tabular}{lr}
\hline \multicolumn{1}{c}{ Variable $(\mathbf{n}=\mathbf{9})$} & \multicolumn{1}{c}{ Values } \\
\hline Age at pre-Fontan catheterization, y & $2.3 \pm 0.3$ \\
Mean PA pressure, $\mathrm{mm} \mathrm{Hg}$ & $13.6 \pm 2.1$ \\
PVR, Wood units. ${ }^{2}$ & $1.5 \pm 0.4$ \\
Qp:Qs & $0.6 \pm 0.1$ \\
RVEDP, $\mathrm{mm} \mathrm{Hg}$ & $10.4 \pm 1.5$ \\
Oxygen saturations, $(\%)$ & $84.6 \pm 1.7$ \\
Cardiac index, $\mathrm{L} / \mathrm{min} / \mathrm{m}^{2}$ & $4.5 \pm 0.7$ \\
Nakata index $\left(\mathrm{mm} / \mathrm{m}^{2}\right)$ & $231(178-343)$ \\
\hline
\end{tabular}

Values are median $(\mathrm{IQR}), \mathrm{n} / \mathrm{N}(\%)$, or mean $\pm \mathrm{SD}$. Complete data set. $P A$, Pulmonary artery; $P V R$, pulmonary vascular resistance; $Q p$, pulmonary blood flow; $Q s$, systemic blood flow; $R V E D P$, right ventricular end-diastolic pressure

SVR trial. ${ }^{1,2,4,13,14}$ However, the use of the RV to PA conduit in the form of PTFE also has potential disadvantages. Mechanical kinking of the graft and perioperative bleeding are well-described early complications. ${ }^{114}$ Thrombosis of the graft and PA distortion can be troublesome issues in the postoperative period. ${ }^{1,4}$ The RV to PA conduit is also associated with risk of reintervention in the interstage period. ${ }^{1,2,15}$ Late deterioration of $\mathrm{RV}$ function is a major concern as follow-up studies of SVR trial indicate. ${ }^{3,16}$ Studies have suggested that the volume load from the free insufficiency of a valveless conduit may play as much a role as the ventricular incision in deterioration of RV function over time. ${ }^{4,17,18}$

At our institute, we prefer to use the RV to PA conduit rather than the Blalock-Taussig-Thomas shunt for stage 1 procedure. To overcome some of the limitations associated with PTFE tube as an RV to PA conduit, we have advocated the use of valved segment of FVH as RV to PA conduit. ${ }^{6}$ The FVH has natural endothelial lining that makes it less thrombogenic, resistant to infection, and hemostatic. ${ }^{5,19,20}$ The thin pliable tissue is ideal for anastomosis to the delicate distal PA in neonates and can be directly anastomosed to a limited RV incision without the necessity of hood simplifying the technical aspects of the operation. The natural pliability of the tissue makes it less prone to kinking and mechanical obstruction. ${ }^{20}$ The most important advantage of the $\mathrm{FVH}$ as RV to PA conduit is that it is valved (multiple valves along the length), potentially minimizing the risk of insufficiency and volume overloading of the single ventricle. Additional volume overloading of the RV from free insufficiency of conduit during the interstage period may play a crucial role in late deterioration of RV function. ${ }^{4,17,18}$

As hypothesized, the perioperative bleeding associated with the use of FVH in our series was extremely low. None of the patients needed surgical reentry or clotting factors during the postoperative period. The hourly chest tube output in the first 24 hours after operation was no more than $1 \mathrm{~mL} / \mathrm{kg}$.

\section{Femoral Vein Homograft Function}

We never observed any thrombosis of the FVH in any of our patients, including the 4 patients weighing less than $2.5 \mathrm{~kg}$ despite the inconsistent use of antiplatelet agents. We also did not encounter any instances of aneurysm, endocarditis, or kinking of the branch pulmonary arteries, which are well-described problems in other series. ${ }^{1,4,13,14}$ As mentioned in the "Results" section, the valve in the FVH remained largely competent during the first month, but most of them progressed to free insufficiency by the time of the stage 2 procedure. In addition to the inevitable insufficiency, the FVH is vulnerable to stenosis at the anastomotic ends and occasionally at the valvar level. The rate of intervention on the $\mathrm{FVH}$ during the interstage period was equivalent to PTFE conduit in a comparative study published by our group ${ }^{7}$ and equivalent to that reported in other series. ${ }^{2,15,17,18,21,22}$

\section{Pulmonary Artery Growth}

Hypoplasia of the branch pulmonary arteries can have deleterious effects on a circulation that will ultimately be dependent on passive venous return, although there is no clear consensus on the optimum size of branch pulmonary arteries for the Fontan operation. ${ }^{8,23-26}$ However, we do know that larger PA size and PA index are associated with better patient survival after the Fontan procedure. ${ }^{24}$ Against this background, we defined good PA growth as a Nakata index greater than $200 \mathrm{~mm}^{2} / \mathrm{m}^{2}$. The RV to PA conduit in the form of PTFE in general is associated with poorer PA growth, as also described by Sano and colleagues. ${ }^{1}$ In the SVR trial, the median Nakata index in the RV to PA conduit group was 145 with an IQR of 110 to 197. ${ }^{2}$ In addition, the SVR trial showed that infants with an RV to PA conduit had a greater need for intervention, both surgical and transcatheter, on the branch pulmonary arteries, as also confirmed by multiple other studies. $^{2,3,15,17,21}$ This risk of increased reintervention on the branch pulmonary arteries continued well beyond the Fontan operation. ${ }^{18}$ On the contrary, one of the biggest positive outcomes associated with the use of FVH was the impressive growth of the branch pulmonary arteries in most of our patients in comparison with the PTFE tube, a study previously published by our group. ${ }^{7}$ The branch pulmonary arteries were well developed by the time of the BDG operation (median Nakata index was $228 \mathrm{~mm}^{2} / \mathrm{m}^{2}$ with an IQR of 107 to $341 \mathrm{~mm}^{2} / \mathrm{m}^{2}$ ) and continued to be good at the time of Fontan operation. Eleven of the 19 patients (excluding the 2 hybrid patients) exhibited a Nakata index above $200 \mathrm{~mm}^{2} / \mathrm{m}^{2}$ at the time of BDG, and 6 of the 9 patients who underwent Fontan operation met this cutoff. The improved size of the branch 


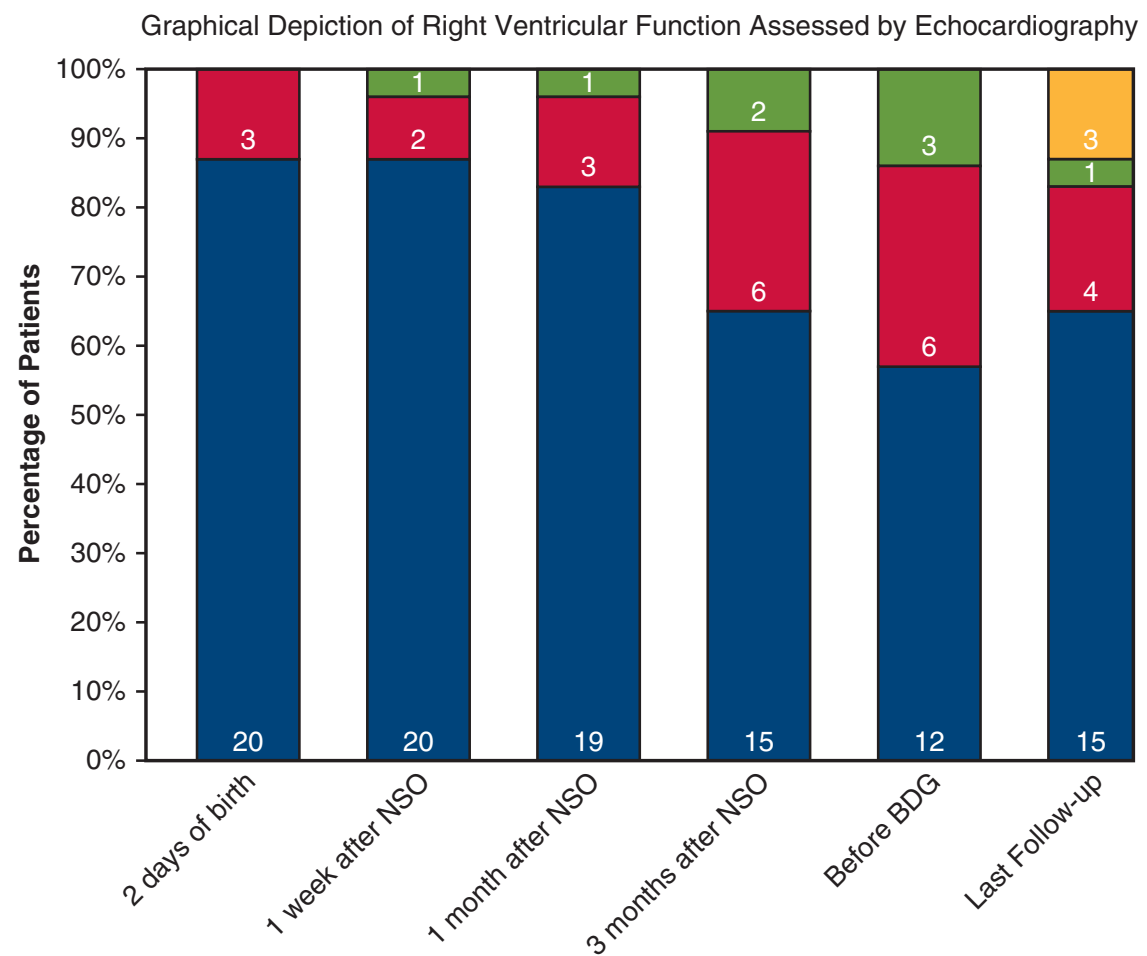

$\underline{\text { RV Function on Echo }}$
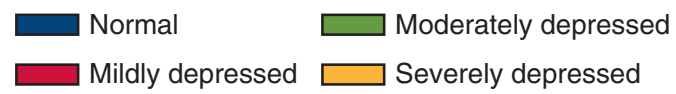

FIGURE 2. Graphical depiction of right ventricular function assessed by echocardiography at 6 time points. Bars show that $87 \%$ of patients with normal function 1 week after the Norwood Sano Operation ( $9 \%$ mild and $4 \%$ moderate dysfunction). Before the BDG, $57 \%$ of patients had normal function ( $29 \%$ mild, 14\% moderate dysfunction), and at latest follow up 66\% were normal (17\% mild, $4 \%$ moderate, and $13 \%$ severe dysfunction). Ordinal logistic regression with the Wald test using a Bonferroni adjustment for multiple comparisons and accounting for correlation within the same patient indicated no significant differences in the distribution of RV function (normal, mild, moderate, severe) at any time point compared with pre-BDG (all $P>.1$ ). $B D G$, Bidirectional Glenn; $N S O$, Norwood-Sano operation; $R V$, right ventricle.

pulmonary arteries and minimal need for surgical or transcatheter intervention on branch pulmonary arteries may be a consequence of femoral valve competence and greater Qp:Qs provided early on.

\section{Right Ventricular Function}

The protection against volume overload afforded by a competent RV to PA conduit in the early postoperative course may be responsible for the extremely stable hemodynamics witnessed in our patients after the stage I procedure. The gold standard for the measurement of intrinsic RV function is by conductance catheterization; however, this method is not used in routine clinical practice. ${ }^{27}$ Cardiac magnetic resonance imaging (MRI) is the method of choice in quantification of RV systolic function; however, it is limited by availability and the need for sedation or anesthesia. ${ }^{28}$ The assessment that correlates best to cardiac MRI is the echocardiographic assessment by experienced cardiologists. ${ }^{29}$ The SVR trial used biplane pyramidal method for assessment of RV function, a software that we do not use in our echocardiographic laboratory. ${ }^{2}$ We used subjective assessment of RV function by 2 experienced cardiologists for this study. The RV function was well preserved as assessed by transthoracic echocardiogram 1 week after the Norwood operation. The low inotrope score and low need for ECMO are further proof of the good function of RV early on. The function of the RV continued to be largely preserved, although a small decline was noted by the time of the BDG operation. At a mean follow-up period of 30 months, the RV function was well preserved in most patients. The only patients who developed deterioration of RV function after stage 1 operation had documented chromosomal disorder (Turner syndrome), severe extracardiac anomaly (hydrocephalus and complex airway issues), severe noncompaction of $\mathrm{RV}$, or recurrent myocarditis, all known risk factors for poor outcome in HLHS. ${ }^{30-32}$ In the SVR study, a decline in function of the RV was noted in the RV to PA conduit group by the time of Fontan 
operation (pre-Fontan minus 14-month mean, $-3.25 \% \pm 8.24 \%$ vs $0.99 \% \pm 8.80 \% ; P=.009) .{ }^{3} \mathrm{We}$ did not notice any decline in RV function in our patients who underwent Fontan operation or those awaiting Fontan operation (Figure 2). Avoidance of volume overload by a competent valve in the early postoperative course may favorably affect remodeling of the RV as it adapts to pump blood in parallel pathways and may be the prime reason for preservation of $\mathrm{RV}$ function observed at follow-up in our group of patients. Other groups have described the use of valved RV to PA conduits during Norwood stage 1 procedure with no apparent benefit over nonvalved conduits. ${ }^{18}$ However, the conduits that were used were composite tubes of various homograft valves anastomosed to PTFE tubes. The presence of multiple circumferential suture lines within the conduit, lack of normal compliance of vessel wall, and anastomosis of a rigid tube to the ventriculotomy may be some of the reasons for failure of benefits over nonvalved conduits.

FVH as an RV to PA conduit for Norwood operation has some drawbacks. There are some technical aspects regarding the use of FVH with a learning curve involved. ${ }^{6}$ The FVH diameter is sometimes larger than advertised, and banding of the FVH may be required to downsize the diameter. ${ }^{6}$ FVH is also more expensive than PTFE. The use of FVH also could result in sensitization of patients.

\section{Study Limitations}

This study represents the experience of a single institution and involves only a small series of patients. Thus, the results are not generalizable. Some variations in observations between our study and other larger series may be related to the differences in operative techniques. A major weakness of the study was that subjective echocardiographic assessment was used to evaluate the function of the RV instead of cardiac MRI. However, the same method was used in all patients. The study also does not provide long-term follow-up data on these patients. Despite these shortcomings, the study provides some vital clues to potentially improve the long-term outcome of patients with HLHS over the current strategies.

\section{CONCLUSIONS}

The use of the femoral vein as an RV to PA conduit in the Norwood Sano operation is safe and associated with good PA growth and preserved ventricular function as assessed by subjective echocardiography. However, transcatheter intervention on the femoral vein conduit may be necessary in the interstage period. The rewards of good PA growth and preservation of ventricular function may be worth the risk of transcatheter intervention in the interstage period.

\section{Webcast}

You can watch a Webcast of this AATS meeting presentation by going to: https://aats.blob.core.windows.net/ media/18May01/24ABC\%202.Congenital \%20SS/S88\% 20-\%20Part\%202/S88_6_webcast_053350634.mp4.

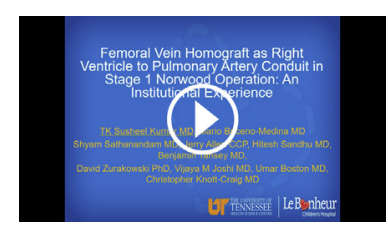

\section{Conflict of Interest Statement}

Authors have nothing to disclose with regard to commercial support.

\section{References}

1. Sano S, Ishino K, Kawada M, Arai S, Kasahara S, Asai T, et al. Right ventriclepulmonary artery shunt in first-stage palliation of hypoplastic left heart syndrome. J Thorac Cardiovasc Surg. 2003;126:504-9.

2. Ohye RG, Sleeper LA, Mahony L, Newburger JW, Pearson GD, Lu M, et al. Comparison of shunt types in the Norwood procedure for single-ventricle lesions. N Engl J Med. 2010;362:1980-92.

3. Newburger JW, Sleeper LA, Frommelt PC, Pearson GD, Mahle WT, Chen S, et al. Transplantation-free survival and interventions at 3 years in the single ventricle reconstruction trial. Circulation. 2014;129:2013-20.

4. Tabbutt S, Dominguez TE, Ravishankar C, Marino BS, Gruber PJ, Wernovsky G, et al. Outcomes after the stage I reconstruction comparing the right ventricular to pulmonary artery conduit with the modified Blalock Taussig shunt. Ann Thorac Surg. 2005;80:1582-90.

5. Sinha P, Moulick A, Jonas RA. Femoral vein homograft for neoaortic reconstruction in Norwood stage 1 operation. Ann Thorac Surg. 2009;87:1309-10.

6. Kumar TKS, Briceno-Medina M, Sathanandam S, Joshi VM, Knott-Craig CJ. Femoral vein homograft as right ventricle to pulmonary artery conduit in stage 1 Norwood operation. Ann Thorac Surg. 2017;103:1969-74.

7. Briceno-Medina M, Kumar TKS, Sathanandam S, Boston U, Perez M, Allen J, et al. Femoral vein homograft as Sano shunt results in improved pulmonary artery growth after Norwood operation. Cardiol Young. 2018;28:118-25.

8. Nakata S, Imai Y, Takanashi Y, Kurosawa H, Tezuka K, Nakazawa M, et al. A new method for the quantitative standardization of cross-sectional areas of the pulmonary arteries in congenital heart diseases with decreased pulmonary blood flow. J Thorac Cardiovasc Surg. 1984;88:610-9.

9. Kalbfleisch JD, Prentice RL. The Statistical Analysis of Failure Time Data. New York: John Wiley \& Sons; 1980. 32-48.

10. Norwood WI, Lang P, Hansen DD. Physiologic repair of aortic atresiahypoplastic left heart syndrome. N Engl J Med. 1983;308:23-6.

11. Bartram U, Grünenfelder J, Van Praagh R. Causes of death after the modified Norwood procedure: a study of 122 postmortem cases. Ann Thorac Surg. 1997;64:1795-802.

12. Bove EL, Lloyd TR. Staged reconstruction for hypoplastic left heart syndrome. Contemporary results. Ann Surg. 1996;224:387-94.

13. Pizarro C, Mroczek T, Malec E, Norwood WI. Right ventricle to pulmonary artery conduit reduces interim mortality after stage 1 Norwood for hypoplastic left heart syndrome. Ann Thorac Surg. 2004;78:1959-63.

14. Sano S, Ishino K, Kado H, Shiokawa Y, Sakamoto K, Yokota M, et al. Outcome of right ventricle-to-pulmonary artery shunt in first-stage palliation of hypoplastic left heart syndrome: a multi-institutional study. Ann Thorac Surg. 2004;78:1951-8.

15. Gist KM, Barrett CS, Graham DA, Crumback SL, Schuchardt EL, Erickson B, et al. Pulmonary artery interventions after Norwood procedure: does type or position of shunt predict need for intervention? J Thorac Cardiovasc Surg. 2013;145:1485-92.

16. Newburger JW, Sleeper LA, Gaynor JW, Hollenbeck-Pringle D, Frommelt PC, Li JS, et al. Transplant-free survival and interventions at 6 years in the Single Ventricle Reconstruction Trial. Circulation. 2018;137:15. 
17. Bentham JR, Baird CW, Porras DP, Rathod RH, Marshall AC. A reinforced rightventricle-to-pulmonary-artery conduit for the stage- 1 Norwood procedure improves pulmonary artery growth. J Thorac Cardiovasc Surg. 2015;149:1502-8.e1.

18. Sandeep N, Punn R, Balasubramanian S, Smith SN, Reinhartz O, Zhang Y, et al. Interstage evaluation of homograft-valved right ventricle to pulmonary artery conduits for palliation of hypoplastic left heart syndrome. J Thorac Cardiovasc Surg. 2018;155:1747-17455.e1.

19. Seery TJ, Sinha P, Zurakowski D, Jonas RA. Femoral vein homograft for neoaortic reconstruction in the Norwood stage 1 operation: a follow-up study. $J$ Thorac Cardiovasc Surg. 2013;146:550-6.

20. Schiller O, Sinha P, Zurakowski D, Jonas RA. Reconstruction of right ventricular outflow tract in neonates and infants using valved cryopreserved femoral vein homografts. J Thorac Cardiovasc Surg. 2014;147:874-9.

21. Reinhartz O, Reddy VM, Petrossian E, MacDonald M, Lamberti JJ, Roth SJ, et al. Homograft valved right ventricle to pulmonary artery conduit as a modification of the Norwood procedure. Circulation. 2006;114(1 Suppl):I594-9.

22. Said SM, Dearani JA. Norwood valved Sano shunt: Early reward versus late penalty? J Thorac Cardiovasc Surg. 2018;155:1756-7.

23. Fontan F, Fernandez G, Costa F, Naftel DC, Tritto F, Blackstone EH, et al. The size of the pulmonary arteries and the results of the Fontan operation. J Thorac Cardiovasc Surg. 1989;98:711-9.

24. Girod DA, Rice MJ, Mair DD, Julsrud PR, Puga FJ, Danielson GK. Relationship of pulmonary artery size to mortality in patients undergoing the Fontan operation. Circulation. 1985;72:I193-6.

25. Bridges ND, Farrell PE Jr, Pigott JD, Norwood WI, Chin AJ. Pulmonary artery index. A nonpredictor of operative survival in patients undergoing modified Fontan repair. Circulation. 1989;80:I216-21.

26. Itatani K, Miyaji K, Nakahata Y, Ohara K, Takamoto S, Ishii M. The lower limit of the pulmonary artery index for the extracardiac Fontan circulation. J Thorac Cardiovasc Surg. 2011;142:127-35.

27. Bellsham-Revell HR, Simpson JM, Miller OI, Bell AJ. Subjective evaluation of right ventricular systolic function in hypoplastic left heart syndrome: how accurate is it? J Am Soc Echocardiogr. 2013;26:52-6.

28. Muthurangu V, Taylor AM, Hegde SR, Johnson R, Tulloh R, Simpson JM, et al. Cardiac magnetic resonance imaging after stage I Norwood operation for hypoplastic left heart syndrome. Circulation. 2005;112:3256-63.

29. Buechel EV, Kaiser T, Jackson C, Schmitz A, Kellenberger CJ. Normal right- and left ventricular volumes and myocardial mass in children measured by steady state free precession cardiovascular magnetic resonance. J Cardiovasc Magn Reson. 2009; 11:19.

30. Patel A, Hickey E, Mavroudis C, Jacobs JP, Jacobs ML, Backer CL, et al. Impact of noncardiac congenital and genetic abnormalities on outcomes in hypoplastic left heart syndrome. Ann Thorac Surg. 2010;89:1805-13.

31. Alsoufi B, Gillespie S, Mahle WT, Deshpande S, Kogon B, Maher K, et al. The effect of noncardiac and genetic abnormalities on outcomes following neonatal congenital heart surgery. Semin Thorac Cardiovasc Surg. 2016;28:105-14.

32. Tabbutt S, Ghanayem N, Ravishankar C, Sleeper LA, Cooper DS, Frank DU, et al. Risk factors for hospital morbidity and mortality after the Norwood procedure: a report from the Pediatric Heart Network Single Ventricle Reconstruction trial. J Thorac Cardiovasc Surg. 2012;144:882-95.

Key Words: hypoplastic left heart syndrome, Norwood operation, outcomes

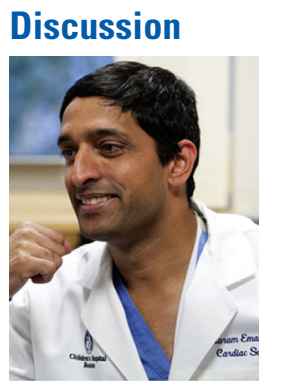

Dr Sitaram Emani (Boston, Mass). I want to challenge you a bit about indications for using this valved conduit. You claim that the benefits have to do with thrombosis prevention, avoid PA distortion, improved right ventricular function, and hopefully a mortality benefit. It appears that mortality is not different compared with what we would normally expect for nonvalved conduit. Thrombosis is rare in the PTFE group. With regard to PA morphology, based on the angiogram shown, PAs appear dilated to some degree, and I wonder if you may contend with excess pulmonary blood flow compared with what you might get with a traditional valveless conduit. Sure your PAs are larger than those seen after valveless conduit, but do they need to be that big? And finally, if you ultimately end up with regurgitation of the conduit after a few weeks, are you really getting a benefit in terms of preventing right ventricular volume overload.

I want to specifically ask the question, what do you think are the benefits of this valved RV-PA conduit over a PTFE graft and why should we pursue this approach?

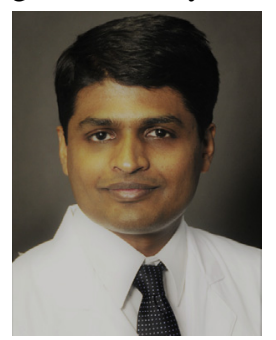

Dr T. K. Kumar (Memphis, Tenn). I agree that thrombosis is probably an exaggerated danger these days with the use of antiplatelet agents. On the other hand, if the patient needs a secondary procedure such as G-tube placement, one can safely stop aspirin or other antiplatelet agents when the femoral vein is used as RV to PA conduit because they are nonthrombogenic compared with PTFE graft.

The real benefit of the femoral vein as an RV to PA conduit is the early preservation of RV function. Granted that the femoral vein valves tended to last for only approximately 6 to 8 weeks, but I think the early preservation of $\mathrm{RV}$ function in those first few weeks makes a huge difference in the long run. The patients tend to do well in the early postoperative course. I think if you can preserve the RV function the first couple of weeks, it translates into better outcomes in the long run. For exactly the same reasons, we have been trying to do the Glenn operation earlier while the femoral vein is still competent. I believe this will result in long-term benefits.

Dr Emani. The next question has do with some technical aspects of the procedure. As you know, we also prefer valved RV-PA conduits at stage 1 operation. With regard to the valve itself, we use an external stent on the valved portion of the conduit, inspired by experience with the Melody valve. We find that the valve competence is better with the external stent; in fact, it lasts up to the time of the Glenn, whereas the unsupported valved conduit presented in your series appears to become incompetent much sooner. A second issue is your choice to use the smallest part of the femoral vein graft for branch PA connection. Your incidence of PA interventions, approximately 35\%, may be reduced if you actually used a larger size femoral vein graft and constrained merely the valved portion at the time of the original operation to adjust pulmonary blood flow to the appropriate degree.

Dr Kumar. Excellent suggestion, once again. I know Dr Richard Jonas and his group at Washington, DC, have been using femoral vein in biventricular repair, and they have 
reported good clinical outcomes. However, the femoral vein does become incompetent at some stage, although they seemed to last longer in biventricular repairs compared with our series. Your idea of placing a stent outside the valve to improve longevity is worth exploring.
The reason we have tended to shy away from using larger veins is because we still do not know how the external band could affect the valve function. But that's something we have been thinking of doing as we gain more confidence with this sort of repair. 


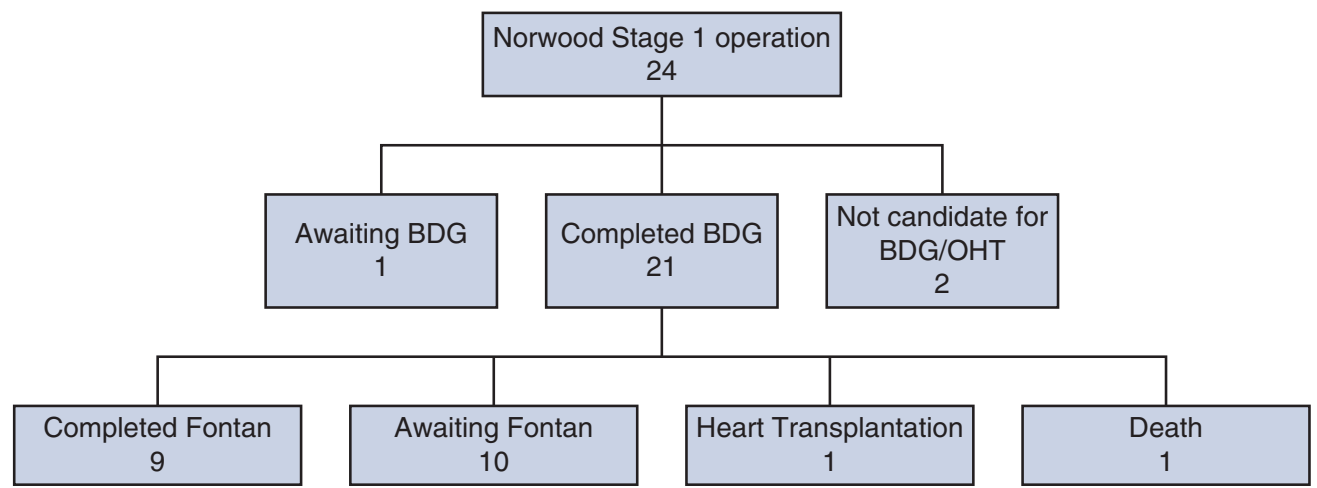

FIGURE E1. Flow chart of patient course after stage 1 Norwood operation. $B D G$, Bidirectional Glenn; $O H T$, orthotopic heart transplantation.

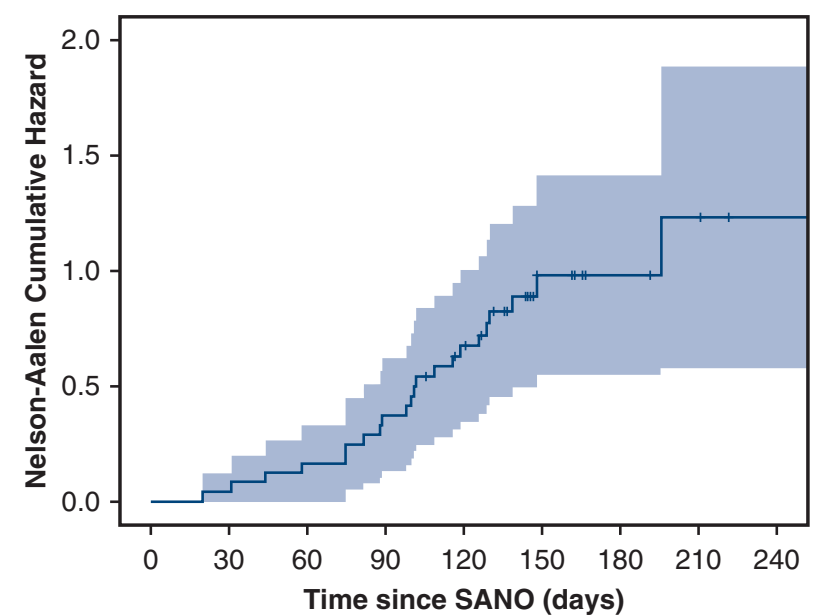

FIGURE E2. Nelson-Aalen cumulative hazard estimate for reintervention since Norwood Sano operation. The cumulative hazard since the NorwoodSano operation, which simply means that all reinterventions are analyzed as well as the patients with no reinterventions (ie, censored observations). The shaded area represents the $95 \%$ confidence interval around the estimated cumulative hazard. The Nelson-Aalen estimator was used to estimate the cumulative hazard based on the sum of reintervention events. The tick marks denote the time points that correspond to censoring. $S A N O$, Norwood-Sano operation.
TABLE E1. Cardiac catheter interventions

\begin{tabular}{lccc}
\hline & $\begin{array}{c}\text { Interstage } \\
\text { period }\end{array}$ & $\begin{array}{c}\text { After } \\
\text { BDG }\end{array}$ & $\begin{array}{c}\text { After } \\
\text { Fontan }\end{array}$ \\
\hline $\begin{array}{l}\text { Balloon angioplasty } \\
\text { RV to PA conduit }\end{array}$ & 16 & NA & NA \\
Branch PA & 1 & 2 & 0 \\
Stent placement & & & \\
RV to PA conduit & 7 & NA & NA \\
Branch PA & 0 & 2 & 0 \\
\hline
\end{tabular}

Total number of catheter interventions on RV to PA conduit or branch pulmonary arteries. Some patients received multiple procedures. Complete data set. $B D G$, Bidirectional Glenn; $R V$, right ventricle; $P A$, pulmonary artery; $N A$, not applicable. 